\title{
STUDIES ON COPPER METABOLISM. XXXI. ERYTHROCYTE COPPER *
}

\author{
By G. S. SHIELDS, $\dagger$ H. MARKOWITZ, W. H. KLASSEN, G. E. CARTWRIGHT and \\ M. M. WINTROBE \\ (From the Department of Medicine, University of Utah College of Medicine, Salt Lake City, Utah)
}

(Submitted for publication June 12, 1961; accepted July 27, 1961)

The isolation and characterization of a cuproprotein, erythrocuprein, from normal human erythrocytes have been described recently (1-3). Preliminary studies indicated that normal human erythrocytes contain about 30 to $36 \mathrm{mg}$ of erythrocuprein per $100 \mathrm{ml}$ of packed cells (1). Since erythrocytes are known to hold about $100 \mu \mathrm{g}$ of copper per $100 \mathrm{ml}$ of packed cells (4), and since erythrocuprein carries $3.4 \mu \mathrm{g}$ of copper per $\mathrm{mg}$ of protein, we suggested that erythrocuprein accounts for most of the copper in erythrocytes.

It became apparent in the course of further investigation that the anti-erythrocuprein serum used in the preliminary studies contained antibody to an erythrocyte component other than erythrocuprein and that the erythrocuprein concentrations reported were erroneously high. A modified technic for purification of erythrocuprein, as well as immunological evidence for the homogeneity of the purified product, are presented in this report. We shall also report studies of erythrocuprein in normal human erythrocytes and in those from patients with various diseases. Since erythrocuprein accounted for only about 60 per cent of the erythrocyte copper, observations are included on the preliminary separation of an additional erythrocyte copper component(s).

\section{METHODS}

Preparation of erythrocuprein. Erythrocuprein was prepared from normal human erythrocytes by a modification of the method described previously (1). The sub-

\footnotetext{
* This investigation was supported in part by Contract AT(11-1)-82, Project 6, between the University of Utah and the U. S. Atomic Energy Commission, and in part by Research Grant A-4489 and Graduate Training Grant 2A-5098 from the National Institute of Arthritis and Metabolic Diseases. A preliminary report of some of the studies described here was presented at the 138th meeting of the American Chemical Society, New York, N. Y., September 11, 1960.

$\dagger$ Present address: Dept. of Medicine, University of Cincinnati, Ohio.
}

stances recovered from the lead acetate precipitation (step 3) were dialyzed free of phosphate ion and stored as a lyophilized powder (LP); 1 to $2 \mathrm{~g}$ of LP was chromatographed (Figure 1A) on a $5 \mathrm{~cm}(47 \mathrm{~mm}$ internal diameter $) \times 40 \mathrm{~cm}$ column containing $100 \mathrm{~g}$ diethylaminoethyl (DEAE)-cellulose, prepared by the method of Peterson and Sober (5). A linear phosphate concentration gradient with a constant $\mathrm{pH}$ of 6.8 was used. The erythrocuprein-containing fractions were identified by the high copper to nitrogen ratio and the reaction with specific antiserum in the agar diffusion technic, as described below. The fractions containing erythrocuprein from several chromatograms were then pooled and rechromatographed (Figure 1B) under conditions identical with those used in the first chromatogram.

The erythrocuprein obtained was homogeneous in the ultracentrifuge. The molecular weight of the protein, determined by the Archibald approach to equilibrium as modified by Schachman (6), was $31,000 \pm 6$ per cent. The copper $(\mu \mathrm{g})$ to nitrogen $(\mathrm{mg})$ ratio was 23.0.

Preparation of antiserum. Rabbits were immunized at weekly intervals for 4 weeks. After a rest period of 1 month a second course of four weekly injections was given. Each subcutaneous injection contained erythrocuprein $(0.25 \mathrm{mg})$ or LP $(20 \mathrm{mg})$ dissolved in $0.5 \mathrm{ml}$ of 0.85 per cent sodium chloride, $0.5 \mathrm{ml}$ of 15 per cent Arlacel A (vol/vol) in Bayol F, and $1 \mathrm{mg}$ of heat-killed tubercle bacilli. After immunization was complete the serums from several rabbits were pooled and merthiolate was added to the serum to a final concentration of $1: 10$,000 . The pooled antiserum was stored at $5^{\circ} \mathrm{C}$.

Evidence for the immunologic homogeneity of antierythrocuprein serum. The agar double diffusion technic of Halbert, Swick and Sonn (7) was used as a criterion of immunologic homogeneity of both the purified erythrocuprein and the anti-erythrocuprein serum. Threetenths $\mathrm{ml}$ of either antiserum (undiluted or diluted 1:1) or antigen ( $1 \mathrm{mg}$ per $\mathrm{ml}$ in saline) was pipetted into each well. The agar plates were incubated at room temperature and observed at approximately 12-hour intervals for 3 to 12 days.

Erythrocuprein (E-I), prepared as described in the previous publication (1), and antiserum (AS-I) to this batch of erythrocuprein were available for study. These preparations, as well as erythrocuprein purified chromatographically (E-II), were tested by the agar double diffusion technic. Typical results are presented diagrammatically in Figure 2.

${ }^{1}$ Arlacel A (mannide monooleate), Atlas Powder Co.; Bayol F, Penola Oil Co. 


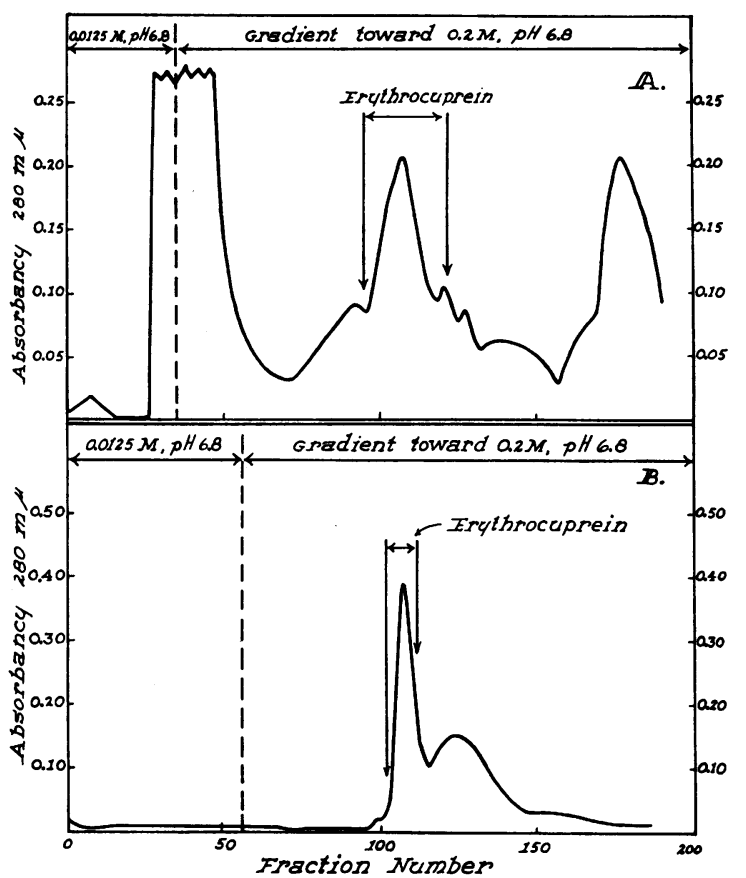

Fig. 1. Chromatograms of AN extract (LP) PREPARED FROM A HEMOLYSATE OF NORMAL HUMAN ERYTHROCYTES. The lyophilized powder containing erythrocuprein was dissolved in $0.0125 \mathrm{M}$ phosphate buffer and chromatographed on DEAE-cellulose. The fractions containing erythrocuprein (A) were pooled and rechromatographed (B) in order to obtain highly purified erythrocuprein.

When E-I was compared in the agar-diffusion procedure with a hemolysate prepared from a normal adult subject (H-A) by the use of AS-I, a single band developed (Figure 2a) which exhibited a reaction of identity (8). When hemolysates prepared from 12 samples of normal umbilical vein blood ( $\mathrm{H}-\mathrm{F})$ were tested in the same manner, reactions suggesting a contaminating antigen were observed (Figure 2, b and c). Therefore, in an effort to confirm the presence of a contaminating antigen, various fractions obtained by chromatography (Figure $1 \mathrm{~A}$ ) of the lyophilized powder (LP) were tested with AS-I. The contaminating antigen, referred to as $\mathrm{CA}$, was localized in the initial effluent from the column (0.0125 $\mathrm{M}$ phosphate buffer, $\mathrm{pH} 6.8)$ and was entirely free of copper. When CA was tested with AS-I, a single band was observed which gave a reaction of partial identity with E-I (Figure 2d). Erythrocuprein (E-I), to which CA had been added, reacted with AS-I to form two bands (Figure 2e), indicating that the small amount of $\mathrm{CA}$ in the erythrocuprein (E-I) was not resolved in most instances by the agar diffusion technic.

Serial absorption of AS-I with CA resulted in an antiserum that no longer reacted with $C A$ (Figure 2f). This absorbed antiserum (AS-I absCA) gave only one precipitin band when tested against E-I and H-F (Figure $2 \mathrm{~g}$ ).
Antiserum prepared from E-II (AS-II) reacted with $\mathrm{E}$-II but not with $\mathrm{CA}$ (Figure $2 \mathrm{~h}$ ) and the reaction with E-II was identical with that between AS-II and E-I (Figure 2i). Only one band was observed when AS-II was used to compare E-II with H-A, H-F, and LP (Figure $2, \mathrm{j}, \mathrm{k}$, and 1 ).

Thus, E-I contained a small amount of a highly antigenic impurity (CA). This could be demonstrated in the agar double diffusion technic only by enriching the erythrocuprein preparation with the contaminant. Erythrocuprein preparations that were purified by chromatography on DEAE-cellulose were free of this impurity. Antiserum (AS-II) prepared from the highly purified erythrocuprein (E-II) was used thereafter for the measurement of erythrocuprein.

Measurement of erythrocyte copper and erythrocuprein. Suspensions of human erythrocytes from which the buffy coat had been removed were washed twice with cold 0.85 per cent sodium chloride. The cells were suspended in saline and the volume of packed red cells (VPRC) was determined. Aliquots of the suspension $(3.0 \mathrm{ml})$ were taken in duplicate for the determination of eryth-

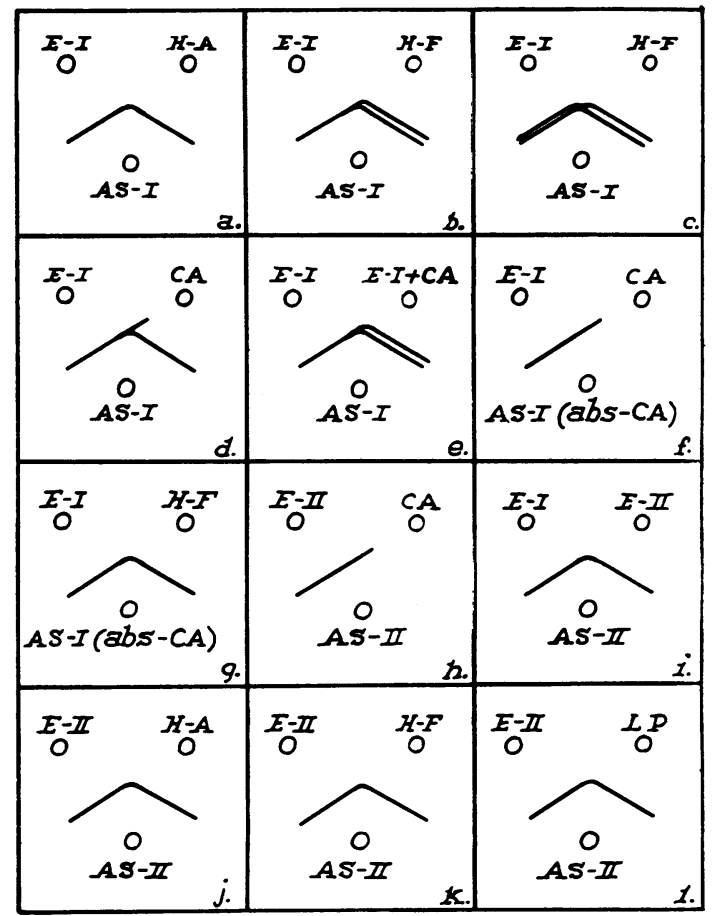

Fig. 2. Diagrammatic Representation of agar DOUBLE DIFFUSION PLATES. E-I, erythrocuprein prepared as described previously (1) ; E-II, erythrocuprein purified chromatographically; AS-I, antiserum to E-I; AS-II, antiserum to E-II; H-A, hemolysate of normal adult erythrocytes; $\mathrm{H}-\mathrm{F}$, hemolysate of umbilical vein erythrocytes; CA, contaminating antigen; AS-I absCA, AS-I absorbed with the contaminating antigen (CA); LP, lyophilyzed powder used as the starting material in the isolation of erythrocuprein. 
rocyte copper (9) ; 4-ml aliquots of the erythrocyte suspension were hemolyzed by freeze-thawing three times and diluted to $25 \mathrm{ml}$ with saline. The diluted hemolysate was cleared of stroma by centrifugation at $15,000 \mathrm{G}$ for 30 minutes and stored at $-40^{\circ} \mathrm{C}$.

The erythrocuprein content of a 1-ml aliquot of the hemolysate was determined by the quantitative precipitin technic (10). The anti-erythrocuprein serum (AS-II) was calibrated with erythrocuprein (E-II), as described previously (1). Erythrocuprein was calculated from the calibration curve by the use of an erythrocuprein nitrogen value of 16.53 per cent. The copper in the erythrocyte associated with erythrocuprein was calculated by assuming an erythrocuprein copper content of 0.34 per cent (2).

Evaluation of the inmunochemical estimation of erythrocuprein. When erythrocuprein was added to hemolysates and the erythrocuprein concentration of each hemolysate was determined before and after addition of purified erythrocuprein, between 88 and 95 per cent of the added erythrocuprein was recovered. In an experiment designed to determine whether addition of copper to an erythrocyte suspension in vitro might influence the determination of erythrocuprein, no change was found in the erythrocuprein level, although the concentration of copper in the erythrocytes was increased 650 per cent.

To estimate the reproducibility of the immunochemical method for the measurement of erythrocuprein, blood was drawn from 20 normal male and female subjects, and the values obtained for duplicate samples were compared. The mean difference between duplicates was 2.7 per cent, with a range of 0 to 8.6 per cent. Aliquots were taken periodically over a 4-month period from a sample of diluted hemolysate during storage at $-40^{\circ} \mathrm{C}$. A definite trend of change in values with the period of storage was not observed.

Radioisotope incorporation studies. Copper ${ }^{\text {ot }}$ was obtained from the Oak Ridge National Laboratories as cupric nitrate in $1 \mathrm{M}$ nitric acid. Sodium hydroxide $(5 \mathrm{~N})$ was added to precipitate cupric hydroxide. The precipitate was washed with distilled water to remove sodium nitrate. The moist precipitate was dissolved in acetic acid and the solution evaporated to dryness. The dry cupric $^{64}$-acetate (specific activity of approximately 600 $\mathrm{mc}$ per $\mathrm{g}$ ) was dissolved and diluted with 0.85 per cent sodium chloride to a concentration of approximately 3 $\mu \mathrm{c}$ per $\mathrm{ml}$.

All radioactive samples were counted in a well-type, thallium-activated sodium iodide crystal scintillation counter with an efficiency of 5 per cent for copper ${ }^{\text {ot }}$. The radioactivity was expressed in counts per minute, corrected for background and decay. All batches of radiocopper were checked for decay rate, which was found to correspond to the expected half-life of 12.8 hours for copper ${ }^{\text {et. }}$.

Fifty $\mathrm{ml}$ of freshly drawn blood was added to $12 \mathrm{ml}$ of acid citrate dextrose anticoagulant solution; $1 \mathrm{ml}$ of cupric $^{\text {at }}$-acetate solution was then added. The mixture was incubated under sterile conditions at $37^{\circ} \mathrm{C}$ with constant shaking for various periods of time.
For the study of the transfer of radiocopper between plasma, erythrocytes and erythrocuprein, 2-ml aliquots of the incubation mixture were pipetted in duplicate into counting vials. Each vial was centrifuged and the plasma removed with care to avoid loss of erythrocytes. The cells were washed twice with saline, with the same precautions, and the packed cells were then frozen and thawed three times. The hemolysate was diluted to the original volume with saline and its radioactivity was determined. Throughout these steps the erythrocytes remained in the original counting vial.

For the study of the transfer of radiocopper between plasma and erythrocuprein, the procedure for the quantitative immunochemical measurement of erythrocuprein was modified to allow rapid precipitation of the antigen because of the short half-life of copperes. After the radioactivity of the hemolysate had been determined, the hemolysate was transferred to a centrifuge tube. The erythrocuprein was precipitated by incubation of the hemolysate with $2 \mathrm{ml}$ of antiserum at $37^{\circ} \mathrm{C}$ for 2 hours. After cooling to $4^{\circ} \mathrm{C}$, the precipitate was collected and washed twice with cold saline. The precipitate was then dissolved in $1 \mathrm{~N} \mathrm{NaOH}$, the solution was diluted to $2 \mathrm{ml}$ after transfer to a counting vial, and the radioactivity was determined. Supernatant tests indicated that only about 70 per cent of the erythrocuprein was precipitated under the conditions of these experiments.

To determine the specificity of the immunochemical precipitation of labeled erythrocuprein, the ability of normal rabbit serum and a foreign immune system to precipitate copper ${ }^{\text {ot }}$ from a labeled hemolysate was tested. When $2 \mathrm{ml}$ of normal rabbit serum was added to the hemolysate, no precipitate formed. Addition of $2 \mathrm{ml}$ of rabbit anti-egg albumin serum, followed by an amount of crystalline egg albumin calculated to bring the system to the equivalence point, led to the formation of a copious precipitate. After washing with cold 0.85 per cent sodium chloride, the precipitate contained less than 3 per cent of the hemolysate radioactivity.

The method of chromatography used for the preparation of erythrocuprein was modified for the partial separation of copper $^{84}$-containing substances from a labeled stroma-free hemolysate. Diethylaminoethyl cellulose (DEAE-SF, California Biochemical Foundation) was washed with $1 \mathrm{~N} \mathrm{NaOH}$ followed by $1 \mathrm{M} \mathrm{NaCl}$. It was then washed with $0.2 \mathrm{M}$ sodium phosphate buffer, $\mathrm{pH} 6.0$, until the eluate became free of chloride ion, then with demineralized water until free of phosphate ion and finally with $0.01 \mathrm{M}$ sodium phosphate, $\mathrm{pH}$ 6.0. Twelve $\mathrm{ml}$ of hemolyzed packed cells, prepared from blood exposed to copper ${ }^{04}$-acetate for 8 hours at $37^{\circ} \mathrm{C}$, was centrifuged at $144,000 \mathrm{G}$ for 1 hour at $5^{\circ} \mathrm{C}$ to remove stroma. Five $\mathrm{ml}$ of the clear supernate was dialyzed, with stirring at $5^{\circ} \mathrm{C}$ for 1 hour, against $500 \mathrm{ml}$ of $0.01 \mathrm{M}$ sodium phosphate, $\mathrm{pH}$ 6.0. The dialysis was repeated twice and the equilibrated hemolysate was chromatographed on a $25 \times$ $190 \mathrm{~mm}$ column of DEAE-celulose. Because of the short half-life of copper ${ }^{\text {es }}$, a metering pump (Milton-Roy Minipump) was used to achieve an optimum flow rate of 60 ml per hour. 
TABLE I

Volume of packed red cells, serum copper, total erythrocyte copper and erythrocuprein in normal subjects

\begin{tabular}{|c|c|c|c|c|c|}
\hline Group & $\begin{array}{l}\text { Vol. packed } \\
\text { red cells }\end{array}$ & Serum copper & $\begin{array}{c}\text { Total erythro. } \\
\text { copper }\end{array}$ & Erythrocuprein & $\frac{\mathrm{E} \mathrm{Cu}}{\mathrm{T} \mathrm{Cu}} \times 100^{*}$ \\
\hline Male & $\underset{\text { blood }}{m l / 100 ~ m l}$ & $\underset{\text { serum }}{\mu \mathrm{g} / 100 \mathrm{ml}}$ & $\begin{array}{c}\mu \mathrm{g} / 100 \mathrm{ml} \\
\text { erythro. }\end{array}$ & $\begin{array}{l}\text { mg/100 ml } \\
\text { erythro. }\end{array}$ & $\%$ \\
\hline $\begin{array}{l}\text { Mean } \\
\text { Range }\end{array}$ & $\begin{array}{l}49 \pm 2.4 \\
45-52\end{array}$ & $\begin{array}{r}107 \pm 11.9 \\
82-125\end{array}$ & $\begin{array}{l}89 \pm 8.5 \\
63-96\end{array}$ & $\begin{array}{l}16 \pm 4.4 \\
13-20\end{array}$ & $\begin{array}{l}60 \pm 20.2 \\
47-78\end{array}$ \\
\hline \multicolumn{6}{|l|}{ Female } \\
\hline $\begin{array}{l}\text { Mean } \pm S D \\
\text { Range }\end{array}$ & $\begin{array}{l}44 \pm 2.5 \\
41-49\end{array}$ & $\begin{array}{l}127 \pm 15.5 \\
103-158\end{array}$ & $\begin{array}{l}89 \pm 12.7 \\
72-107\end{array}$ & $\begin{array}{l}17 \pm 7.0 \\
13-26\end{array}$ & $\begin{array}{l}65 \pm 24.0 \\
48-82\end{array}$ \\
\hline \multicolumn{6}{|l|}{ Both groups } \\
\hline $\begin{array}{l}\text { Mean } \pm S D \\
\text { Range }\end{array}$ & $\begin{array}{l}47 \pm 3.4 \\
41-52\end{array}$ & $\begin{array}{l}117 \pm 17.1 \\
82-158\end{array}$ & $\begin{array}{l}89 \pm 11.4 \\
63-107\end{array}$ & $\begin{array}{l}16 \pm 2.9 \\
13-26\end{array}$ & $\begin{array}{l}62 \pm 11.0 \\
47-82\end{array}$ \\
\hline
\end{tabular}

${ }^{*} \mathrm{E} \mathrm{Cu}$, erythrocuprein copper (erythrocuprein in $\mathrm{mg} \times 3.4$ ); $\mathrm{T} \mathrm{Cu}$, total erythrocyte copper.

Ten-ml fractions of the effluent were collected and the absorbance at $280 \mathrm{~m} \mu$ and the copper ${ }^{\text {et }}$ content were determined. The column was washed with $0.01 \mathrm{M}$ phosphate buffer, $\mathrm{pH} 6.0$, until ultraviolet-absorbing materials were no longer eluted. A phosphate concentration gradient to $0.2 \mathrm{M}$ sodium phosphate, $\mathrm{pH} 6.0$, was then used to elute other materials from the column.

Carboxymethyl-cellulose (CM-W, California Biochemical Foundation) was washed (5) and equilibrated with $0.01 \mathrm{M}$ sodium phosphate buffer, $\mathrm{pH}$ 6.0. All fractions containing copper ${ }^{\text {st }}$ that were eluted with $0.01 \mathrm{M}$ phosphate from DEAE-cellulose were pooled and applied to a $25 \times 600 \mathrm{~mm}$ column of CM-cellulose. The CM-cellulose was eluted in successive steps with $0.01 \mathrm{M}$ sodium phosphate buffers at $\mathrm{pH} 6.2,7.0,7.3,7.5$, and 8.4. Ten$\mathrm{ml}$ fractions of the effluent were collected and analyzed as described above.

Other methods and material. Hematologic studies were performed by conventional methods (11). Serum copper was measured by the method of Gubler and co-workers (12) and carbonic anhydrase by the method of Keilin and Mann (13).

The normal subjects used in these investigations were laboratory and office personnel between the ages of 20 and 45. Blood samples were drawn from the individuals without regard to time of day or recent dietary intake.

\section{RESULTS}

Total copper and erythrocuprein in normal human erythrocytes. The volume of packed red cells (VPRC), serum copper concentration, total erythrocyte copper concentration and erythrocuprein concentration were determined in a single sample of blood from each of 20 normal subjects. The results are presented in Table $I$. The values for VPRC, serum copper and total erythrocyte copper are within the normal range of values reported previously from this laboratory $(4,9,11)$.
The mean erythrocuprein concentration in normal individuals was $16 \mathrm{mg}$ per $100 \mathrm{ml}$ of packed erythrocytes. When the copper bound to erythrocuprein was calculated from the erythrocuprein concentration, slightly more than half of the erythrocyte copper was present as erythrocuprein copper. No significant difference between the sexes was noted in this regard.

To determine the degree of variation in total erythrocyte copper and erythrocuprein from week to week in a single individual, these two parameters were measured in two male and two female subjects (Figure 3 ). The variation in both measurements in a single individual during a period of 1 month approximated the variation found in the entire group of normal subjects and was greater than that found in replicate samples. A correlation was not observed between erythrocuprein and total erythrocyte copper in 41 paired determinations $(\mathrm{R}=+0.23 ; \mathrm{p}>0.1)$.

Total erythrocyte copper and erythrocuprein in erythrocytes from patients with alterations in the concentration of serum copper. To investigate the influence of the level of serum copper on the concentrations of total erythrocyte copper and erythrocuprein, serum copper, total erythrocyte copper and erythrocuprein were measured in 17 patients with conditions known to be associated with alterations in serum copper (Table II). In general, in spite of wide variations in serum copper (10 to $322 \mu \mathrm{g}$ per $100 \mathrm{ml}$ ), the total erythrocyte copper and erythrocuprein concentrations did not differ from the normal. In one of the two patients with Wilson's disease and in one of the patients 


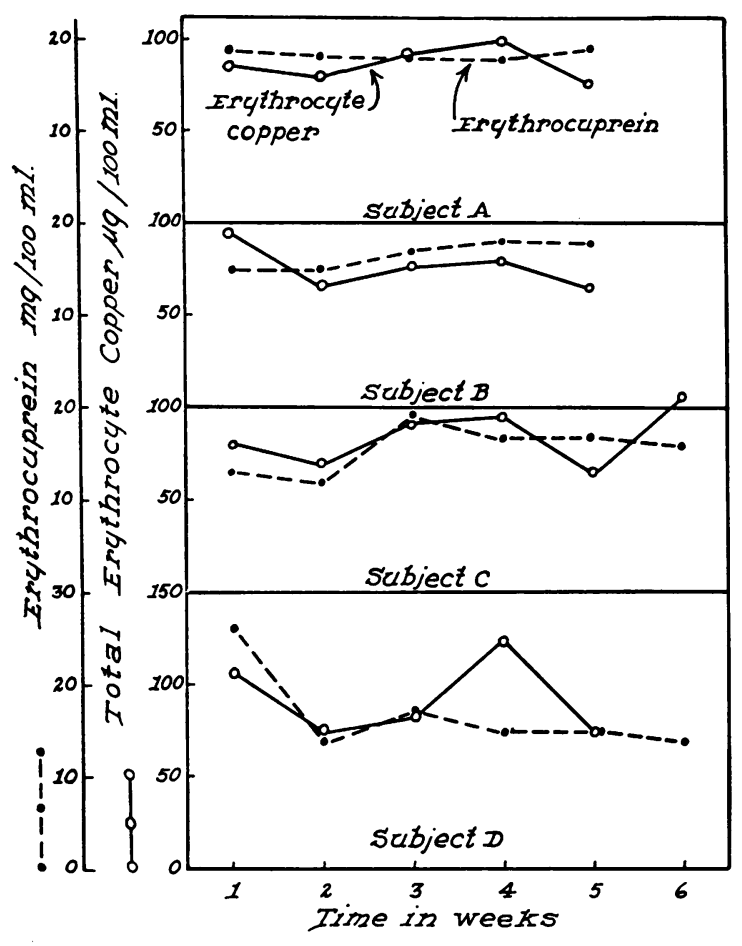

Fig. 3. THE VARIATION IN TOTAL ERYTHROCYTE COPPER AND ERYTHROCUPREIN LEVELS MEASURED AT WEEKLY INTERVALS IN FOUR NORMAL SUBJECTS.

with idiopathic hypocupremia (14), the concentration of erythrocuprein was in the low normal range.

The erythrocuprein concentration was measured in 11 patients ( 3 with thyrotoxicosis, 2 with iron deficiency anemia, 1 with aplastic anemia, 1 with lymphosarcoma, 1 with paroxysmal nocturnal hemoglobinuria, 1 with pyridoxine-responsive anemia, 1 with biliary cirrhosis, and 1 with malignant melanoma) in addition to those presented in Table II. The concentration of erythrocuprein was within the normal range in each case.

Immunochemical identity of erythrocuprein. To determine whether qualitative immunologic differences in erythrocuprein could be detected among individuals, hemolysates were tested with rabbit anti-erythrocuprein serum by the agar double diffusion technic. Hemolysates from 7 normal subjects, 105 patients from the hematology clinic, 40 patients from the wards of the medical and pediatric services and from 3 samples of umbilical vein blood were studied in this fashion. In every case a single zone of precipitation was observed which showed a reaction of identity with purified erythrocuprein. No instance of cross reaction or absence of the zone of precipitation was observed.

Because cuproproteins have been isolated from species other than man (15), erythrocytes from pigs, rabbits, chickens and steers were tested for the presence of erythrocuprein by the agar double diffusion technic. No reaction was found between antihuman erythrocuprein serum and hemolysates from these species. When we used rabbit antihuman erythrocuprein serum to compare a hemolysate of erythrocytes, obtained from a squirrel

TABLE II

Total erythrocyte copper and erythrocuprein in conditions associated with alterations in the concentration of serum copper

\begin{tabular}{|c|c|c|c|c|c|}
\hline Condition & Patients & $\begin{array}{l}\text { Vol. packed } \\
\text { red cells }\end{array}$ & Serum copper & $\begin{array}{c}\text { Total erythro. } \\
\text { copper }\end{array}$ & $\begin{array}{l}\text { Erythro- } \\
\text { cuprein }\end{array}$ \\
\hline Normal subjects & $\begin{array}{l}n o . \\
20\end{array}$ & $\begin{array}{c}m l / 100 m l \\
47 \pm 3.4 \\
(41-52)^{*}\end{array}$ & $\begin{array}{c}\mu g / 100 \mathrm{ml} \\
117 \pm 17.1 \\
(82-158)\end{array}$ & $\begin{array}{c}\mu g / 100 \mathrm{ml} \\
89 \pm 11.4 \\
(63-107)\end{array}$ & $\begin{array}{l}m g / 100 m l \\
16 \pm 2.9 \\
(13-26)\end{array}$ \\
\hline Pregnancy & 10 & $\begin{array}{l}38 \pm 3.6 \\
(34-43)\end{array}$ & $\begin{array}{l}246 \pm 41.0 \\
(187-322)\end{array}$ & $\begin{array}{l}75 \pm 13.6 \\
(54-100)\end{array}$ & $\begin{array}{l}19 \pm 4.4 \\
(15-26)\end{array}$ \\
\hline $\begin{array}{l}\text { Umbilical } \\
\text { vein blood }\end{array}$ & 3 & $\begin{array}{l}59 \\
49\end{array}$ & $\begin{array}{l}68 \\
72 \\
57\end{array}$ & $\begin{array}{r}104 \\
109 \\
95\end{array}$ & $\begin{array}{l}26 \\
15 \\
15\end{array}$ \\
\hline Wilson's disease & 2 & $\begin{array}{l}54 \\
46\end{array}$ & $\begin{array}{l}28 \\
18\end{array}$ & $\begin{array}{l}89 \\
67\end{array}$ & $\begin{array}{l}12 \\
21\end{array}$ \\
\hline $\begin{array}{l}\text { Idiopathic } \\
\text { hypocupremia } \\
\text { of infancy }\end{array}$ & 2 & $\begin{array}{l}18 \\
26\end{array}$ & $\begin{array}{l}10 \\
52\end{array}$ & $\begin{array}{r}162 \\
78\end{array}$ & $\begin{array}{l}13 \\
12\end{array}$ \\
\hline
\end{tabular}

* Range. 
monkey (Saimiri sciureus), with purified erythrocuprein from human subjects, a reaction of partial identity was observed.

Because cuproproteins have been demonstrated in mammalian tissues $(16,17)$, homogenates of human brain, liver and kidney were tested with rabbit anti-erythrocuprein serum. A single precipitin band identical with erythrocuprein was observed in each tissue.

Because the sensitivity of the agar diffusion tests was sufficient to show precipitin bands due to small amounts of blood trapped in the organ before homogenization, quantitative precipitin tests were performed on the supernates obtained from the homogenized tissues (Table III). When the erythrocuprein concentration was corrected for trapped erythrocyte erythrocuprein by calculation from the concentration of hemoglobin in the homogenate, only 1 per cent or less of the total erythrocuprein could be accounted for by the trapped erythrocytes. The erythrocuprein copper in no case represented more than 10 per cent of the total copper found in the sample.

Transfer of copper ${ }^{64}$ between plasma, erythrocytes and erythrocuprein. To determine whether copper added to plasma could be detected in erythrocuprein, copper ${ }^{64}$-acetate was incubated with whole blood at $37^{\circ} \mathrm{C}$ for 12 hours. Aliquots of the incubation mixture were taken at $2,4,8$ and 12 hours for determination of radioactivity in the mixture, in erythrocytes and in erythrocuprein (Figure 4).

In confirmation of earlier studies (18), there was a rapid transfer of copper from plasma to erythrocytes; 82 per cent of the radioactivity added

TABLE III

Erythrocuprein in liver, brain and kidney

\begin{tabular}{clrc}
\hline \hline Organ & \multicolumn{1}{c}{ Diagnosis } & \multicolumn{2}{c}{ Erythrocuprein } \\
\hline \multirow{3}{*}{ Liver } & Myocardial infarction & $\mu g / g^{*}$ & $m g /$ organ \\
& Cerebrovascular accident & 150 & 233 \\
& Congestive heart failure & 260 & 171 \\
& and uremia & 273 \\
& Pyelonephritis & 1,240 & 1,116 \\
& Wilson's disease & 67 & 34 \\
& Wilson's disease & 170 & 244 \\
Brain & Myocardial infarction & 50 & 67 \\
& Huntington's chorea & 80 & 112 \\
Kidney & Myocardial infarction & 90 & 32
\end{tabular}

* Wet tissue.

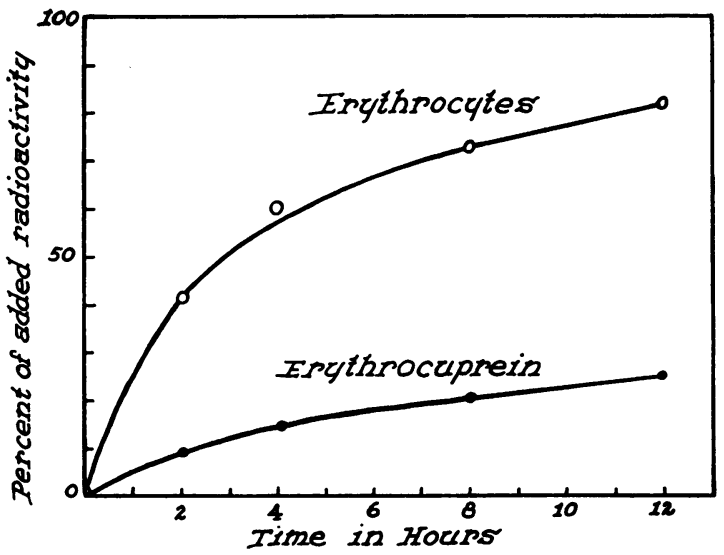

Fig. 4. TRANSFER OF COPPER ${ }^{\text {et }}$ From PLASMa to ERYTHROCYTES AND ERYTHROCUPREIN, AFTER in vitro INCUBATION. The uptake curves are expressed as per cent of the total radioactivity added to the whole blood which was recovered in the erythrocytes and in the erythrocuprein.

to whole blood appeared in the erythrocytes in 12 hours. There was a slow transfer of radiocopper into erythrocuprein during this period. About 25 per cent of the radioactivity added was in erythrocuprein after 12 hours, but as mentioned previously, under the conditions of this experiment not all of the erythrocuprein was precipitated by the antiserum.

Separation of a second soluble erythrocyte copper component from erythrocuprein. Since the studies on the quantitative measurement of erythrocuprein indicated that all of the copper in erythrocytes could not be accounted for in this cuproprotein, an effort was made to separate a second soluble copper component from erythrocuprein. Copper $^{84}$-acetate was incubated with whole blood for 8 hours at $37^{\circ} \mathrm{C}$. The erythrocytes were separated from the plasma, washed, and hemolyzed. The stroma was separated from the soluble hemolysate by centrifugation at $144,000 \mathrm{G}$ for 1 hour at $5^{\circ} \mathrm{C}$. An aliquot of the labeled stroma-free hemolysate was subjected to chromatography on DEAE-cellulose (Figure 5). The fractions under the initial peak, eluted from the column by $0.01 \mathrm{M}$ phosphate buffer, were pooled and were found to contain hemoglobin, carbonic anhydrase activity, and 50 per cent of the radiocopper of the hemolysate.

At approximately the midpoint of the gradient. a peak of radioactivity appeared which contained about 42 per cent of the radioactivity of the 


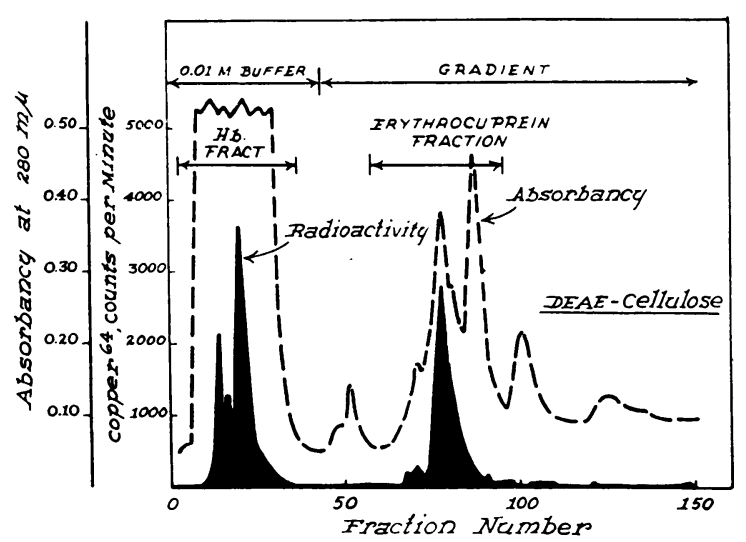

Fig. 5. Chromatogram of a hemolysate of labeled HUMAN ERYTHROCYTES. Erythrocytes were incubated with copper ${ }^{\text {ot }}$ for 8 hours, washed, packed, and hemolyzed. Stroma was removed by centrifugation; $10 \mathrm{ml}$ of the clear hemolysate was dialyzed against $0.01 \mathrm{M}$ phosphate buffer ( $\mathrm{pH}$ 6.0) and chromatographed on DEAE-cellulose. The values on the ordinate refer to the corrected cpm found in each $10-\mathrm{ml}$ effluent fraction.

stroma-free hemolysate. The fractions representing the peak were pooled and an aliquot was incubated with $2 \mathrm{ml}$ of anti-erythrocuprein serum for 2 hours at $37^{\circ} \mathrm{C}$. All of the radioactivity in the aliquot was precipitated by the specific antiserum. In three experiments, from 83 to 100 per cent of the total radioactivity added to the column was recovered in the fractions collected under the two peaks.

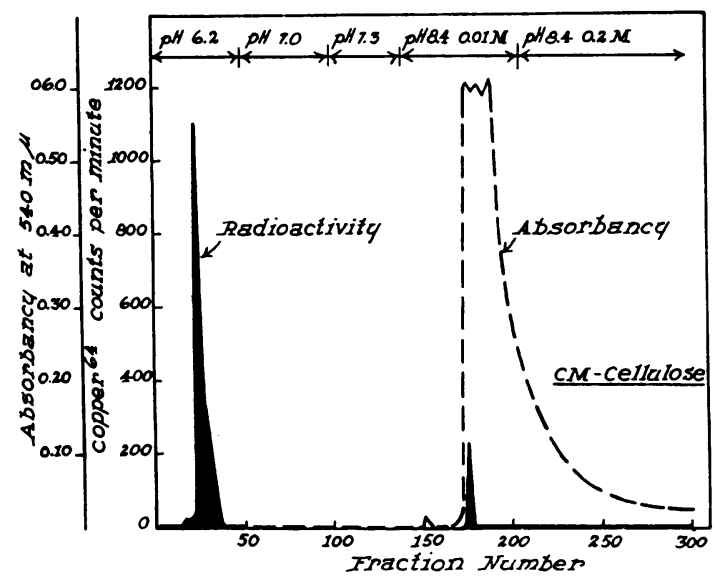

Fig. 6. Chromatogram of the Non-erythrocuprein FRACTION OF LABELED HUMAN ERYTHROCYTES. The fractions from the DEAE-cellulose column (Figure 5) containing the initial peak of radioactivity were chromatographed on CM-cellulose without further treatment. The values on the ordinate refer to the corrected cpm found in each $10-\mathrm{ml}$ effluent fraction.
When the pooled fractions representing the initial peak of radioactivity eluted from the DEAEcellulose were subjected to chromatography on $\mathrm{CM}$-cellulose, all the copper ${ }^{64}$ recovered from the CM-cellulose appeared immediately in the $\mathrm{pH} 6.2$ effluent (Figure 6). This effluent contained all the carbonic anhydrase activity of the original hemolysate. Most of the hemoglobin was adsorbed by the CM-cellulose under these conditions, although the effluent exhilited slight absorbance at $540 \mathrm{~m} \mu$. The fractions representing the radioactive peak were pooled, dialyzed, and lyophilized. The combined fractions contained no erythrocuprein as determined immunochemically. When this material was tested against antiserum to the crude starting material (LP) by the agar double diffusion technic, three antigens were demonstrated. Four protein components were demonstrated by starch gel electrophoresis at $\mathrm{pH} 9.5$. Further purification of the radioactive component $(s)$ of this fraction was not feasible because of the short half-life of copper ${ }^{64}$.

\section{DISCUSSION}

The results of this study indicate that normal human erythrocytes contain $16 \pm 2.9 \mathrm{mg}$ of erythrocuprein per $100 \mathrm{ml}$ of packed cells. Assumed that erythrocuprein contains $3.4 \mu \mathrm{g}$ of copper per $\mathrm{mg}$ of protein (2), erythrocuprein accounts for about 60 per cent of the copper present in erythrocytes. These values are lower than those reported previously (1). In the previous study the erythrocuprein was purified by tricalcium phosphate gel adsorption, and ethanol and ammonium sulfate fractionation. It has now been shown that this material contained a small amount of highly antigenic impurity. The erythrocuprein used in the present study was purified by chromatography and a contaminating antibody could not be demonstrated in the antiserum prepared by the use of this more highly refined preparation.

In agreement with the observation that erythrocuprein does not account for all of the copper in erythrocytes, a second soluble copper component(s) has been separated from hemolysates by column chromatography. The nature of this second copper-containing component(s) is unknown.

The existence of two erythrocyte copper pools was first suggested by studies in copper-deficient 
swine (19). It was noted that the concentration of copper in the erythrocytes of such swine decreased rapidly early in the course of the deficiency from a level of $110 \mu \mathrm{g}$ per $100 \mathrm{ml}$ of packed cells to approximately $67 \mu \mathrm{g}$. Thereafter, in spite of the severity of the copper deficiency there was little further decrease in the erythrocyte copper concentration. Bush and colleagues (18) noted in a later study that when radiocopper was incubated with normal human erythrocytes for 15 to $30 \mathrm{~min}$ utes, radiocopper moved rapidly into and out of the erythrocytes; this fraction of erythrocyte copper was referred to as the "labile pool." However, when erythrocytes were incubated with radiocopper for 24 hours, the radiocopper was transformed in part into a fraction that turned over much more slowly; the copper in this fraction was referred to as the "stable pool."

In the same study (18) it was also demonstrated that, when radiocopper was added to plasma, it entered the "direct-reacting" fraction of plasma copper and did not exchange with the copper in ceruloplasmin. From the studies on the incubation of erythrocytes with radiocopper reported in this paper, it is apparent that radiocopper added to plasma does move into erythrocuprein and into the second fraction.

The studies on the erythrocuprein concentration in erythrocytes from patients with various disease states indicate that the erythrocuprein content is quite constant. In patients with hypercupremia, the concentration of erythrocuprein was not increased. At most only an equivocal reduction in erythrocuprein was observed in patients with severe hypocupremia. Thus, the amount of erythrocuprein in erythrocytes was independent of the ceruloplasmin concentration, since about 95 per cent of the copper in serum is in ceruloplasmin. The failure to detect qualitative differences between individual erythrocupreins from over 150 subjects with a wide variety of blood dyscrasias when tested by agar double diffusion suggests that qualitative as well as quantitative alterations in erythrocuprein in disease are not common, if such do occur.

Erythrocuprein was detected in human liver, kidney and brain in concentrations greater than could be accounted for by the number of erythrocytes present, but the copper in the erythrocuprein fraction of the organs accounted for less than 10 per cent of the total organ copper. Erythrocuprein, on the basis of physicochemical properties, is quite similar to the brain copper protein, cerebrocuprein I, isolated by Porter and Folch (17), but until highly purified cerebrocuprein has been tested against anti-erythrocuprein serum, the identity of these two cuproporteins must remain uncertain. Erythrocuprein can be distinguished from the human hepatocuprein, isolated recently by Shapiro, Morell and Scheinberg (20), on the basis of differences in molecular weight and copper content.

\section{SUMMARY}

1. A chromatographic method for the preparation of immunologically homogeneous erythrocuprein has been described. The physical and chemical properties of the erythrocuprein isolated were similar to those of the erythrocuprein isolated previously.

2. The erythrocuprein concentration was determined by the precipitin technic in erythrocytes. from 20 normal subjects. The mean value \pm 1 SD was $16 \pm 2.9 \mathrm{mg}$ per $100 \mathrm{ml}$ of packed cells. Since erythrocuprein contains $3.4 \mu \mathrm{g}$ of copper per $\mathrm{mg}$ of protein, the copper in erythrocuprein accounts for about 60 per cent of the total erythrocyte copper.

3. Quantitative and qualitative study of erythrocuprein in erythrocytes from patients with a variety of disorders failed to disclose alterations from the normal. The concentration of erythrocuprein was independent of alterations in the concentration of serum copper.

4. Erythrocuprein was detected in human brain, liver and kidney.

5. Hemolysates of pig, rabbit, chicken and bovine erythrocytes failed to react with antihuman erythrocuprein rabbit serum in the agar diffusion system. A reaction of partial identity was obtained with a hemolysate of squirrel monkey (Saimiri sciureus) erythrocytes.

6. A second erythrocyte copper fraction has been separated from erythrocuprein by chromatography on diethylaminoethyl-cellulose and from hemoglobin by chromatography on carboxymethylcellulose. The nature of the copper compound(s) in this fraction is unknown.

7. When radiocopper was incubated with whole blood, radioactivity was detected both in the 
erythrocuprein and in the second copper-containing fraction.

\section{ACKNOWLEDGMENTS}

We are indebted to Dr. A. Haut for the starch gel electrophoresis studies; to $\mathrm{Mr}$. D. M. Brown for the determination of the molecular weight of erythrocuprein; and to Dr. J. H. Hink, Jr., Cutter Laboratories, Inc., Berkeley, Calif., for the preparation of the crude erythrocuprein starting material (Fraction LP).

\section{REFERENCES}

1. Markowitz, H., Cartwright, G. E., and Wintrobe, M. M. Studies on copper metabolism XXVII. The isolation and properties of an erythrocyte cuproprotein (erythrocuprein). J. biol. Chem. 1959, 234, 40.

2. Kimmel, J. R., Markowitz, H., and Brown, D. M. Some chemical and physical properties of erythrocuprein. J. biol. Chem. 1959, 234, 46.

3. Nyman, P. O. A modified method for the purification of erythrocuprein. Biochim. biophys. Acta 1960, 45, 387.

4. Lahey, M. E., Gubler, C. J., Cartwright, G. E., and Wintrobe, M. M. Studies on copper metabolism. VI. Blood copper in normal human subjects. J. clin. Invest. 1953, 32, 322.

5. Peterson, E. A., and Sober, H. A. Chromatography of proteins. I. Cellulose ion-exchange adsorbents. J. Amer. chem. Soc. 1956, 78, 751.

6. Schachman, H. K. Ultracentrifugation, diffusion, and viscometry in Methods in Enzymology, S. P. Colowick and N. O. Kaplan, Eds. New York, Academic Press, 1957, vol. 4, p. 32.

7. Halbert, S. P., Swick, L., and Sonn, C. The use of precipitin analysis in agar for the study of human streptococcal infections. II. Ouchterlony and Oakley technics. J. exp. Med. 1955, 101, 557.

8. Ouchterlony, O. Diffusion-in-gel methods for immunological analysis. Progr. Allergy 1958, 5, 1.
9. Markowitz, H., Shields, G. S., Klassen, W. H., Cartwright, G. E., and Wintrobe, M. M. A method for the determination of total erythrocyte copper. Analyt. Chem. 1961, 33, 1594.

10. Kabat, E. A., and Mayer, M. M. Experimental Immunochemistry, 1st ed. Springfield, Ill., Thomas, 1948 , p. 20.

11. Cartwright, G. E. Diagnostic Laboratory Hematology, 2nd ed. New York, Grune \& Stratton, 1958.

12. Gubler, C. J., Lahey, M. E., Ashenbrucker, H., Cartwright, G. E., and Wintrobe, M. M. Studies on copper metabolism I. A method for the determination of copper in whole blood, red blood cells, and plasma. J. biol. Chem. 1952, 196, 209.

13. Keilin, D., and Mann, T. Carbonic anhydrase. Purification and nature of the enzyme. Biochem. J. 1940, 34, 1163.

14. Zipursky, A., Dempsey, H., Markowitz, H., Cartwright, G., and Wintrobe, M. M. Studies on copper metabolism. XXIV. Hypocupremia in infancy. J. Dis. Child. 1958, 96, 148.

15. Dawson, C. R., and Mallette, M. F. The copper proteins. Advanc. Protein Chem. 1945, 2, 179.

16. Mann, T., and Keilin, D. Haemocuprein and hepatocuprein, copper-protein compounds of blood and liver in mammals. Proc. roy. Soc. B 1938, 126, 303.

17. Porter, H., and Folch, J. Cerebrocuprein I. A copper-containing protein isolated from brain. $\mathrm{J}$. Neurochem. 1957, 1, 260.

18. Bush, J. A., Mahoney, J. P., Gubler, C. J., Cartwright, G. E., and Wintrobe, M. M. Studies on copper metabolism XXI. The transfer of radiocopper between erythrocytes and plasma. J. Lab. clin. Med. 1956, 47, 898.

19. Lahey, M. E., Gubler, C. J., Chase, M. S., Cartwright, G. E., and Wintrobe, M. M. Studies on copper metabolism II. Hematologic manifestations of copper deficiency in swine. Blood 1952, 7, 1053.

20. Shapiro, J., Morell, A. G., and Scheinberg, I. H. A copper-protein of human liver (abstract). J. clin. Invest. 1961, 40, 1081. 